\title{
Serum neurofilament light chain
}

No clear relation to cognition and neuropsychiatric symptoms in stable MS

Orhan Aktas, MD,* Alina Renner, MSc,* André Huss, PhD, Melanie Filser, MSc, Sharon Baetge, MSc, Nathalie Stute, MSc, Marcia Gasis, MSc, Klaudia Lepka, PhD, Norbert Goebels, MD, Makbule Senel, MD, Jonas Graf, MD, Christian Enzinger, MD, Daniela Pinter, PhD, Gerald Antoch, MD, Bernd Turowski, MD, Hans-Peter Hartung, MD, Philipp Albrecht, MD, Markus Otto, MD, Hayrettin Tumani, MD, and Iris-Katharina Penner, PhD

Neurol Neuroimmunol Neuroinflamm 2020;7:e885. doi:10.1212/NXI.0000000000000885

\section{Abstract}

\section{Objective}

To explore the hypothesis that serum neurofilament light chain (sNfL) indicative of neuroaxonal damage may improve precise disease profiling with regard to cognition and neuropsychiatric symptoms, we analyzed potential associations of sNfL levels with cognitive test scores, fatigue, depression, and anxiety.

\section{Methods}

Patients with relapsing-remitting and secondary progressive MS (SPMS) underwent an elaborated assessment including MRI, various cognitive tests, and patient-reported outcomes. We determined sNfL levels by single molecule array (Simoa) assay. Relationships between sNfL, cognition, neuropsychiatric symptoms, and demographical data were analyzed using correlations, group comparisons, and regressions.

\section{Results}

In 45 clinically stable patients with MS (Expanded Disability Status Scale $=2.73 \pm 1.12$, disease duration $=10.03 \pm 7.49$ years), $40.0 \%$ were cognitively impaired. Mean sNfL levels were $16.02 \pm$ $10.39 \mathrm{pg} / \mathrm{mL}$, with higher levels in the SPMS subgroup $(p=0.038)$. sNfL levels did reliably link neither with the investigated cognitive and affective parameters nor with fatigue levels. The only relationship found in a small subgroup of patients with SPMS $(\mathrm{n}=7)$ with visuospatial learning $(r$ $=-0.950, p=0.001)$ and memory $(r=-0.813 ; p=0.026)$ disappeared when further controlling for age, educational level, and sex.

\section{Conclusions}

In patients with stable MS at less advanced disease stages, sNfL did not convincingly relate to cognitive performance, fatigue, depression, or anxiety and thus may not serve as a surrogate biomarker for neuropsychological status in such populations.

\author{
Correspondence \\ Prof. Dr. Penner \\ iris-katharina.penner@ \\ uni-duesseldorf.de
}




\section{Glossary}

BICAMS = Brief International Cognitive Assessment for MS; BVMT-R = Brief Visuospatial Memory Test - Revised; CBV = cortical brain volume; $\mathbf{C I}=$ cognitive impairment; $\mathbf{C I S}=$ clinically isolated syndrome; $\mathbf{C V}=$ coefficient of variation; $\mathbf{D G V}=$ deep gray matter volume; FoV = field of view; FSL = FMRIB Software Library; MPRAGE = magnetization-prepared rapid acquisition with gradient echo; NBV = normalized brain volume; NfL = neurofilament light chain; SDMT = Symbol Digit Modalities Test; $\mathbf{s N f L}=$ serum NfL; T2-LL $=$ T2 lesion load; TE $=$ echo time; TR $=$ repetition time.

In patients with MS, symptoms such as cognitive impairment (CI), fatigue, and mood disturbances have a detrimental influence on working ability and quality of life, even at early disease stages. ${ }^{1,2}$ Neuroaxonal damage, leading toward the disruption of structural and functional neuronal networks, contributes to the development and progression of irreversible disability including cognitive deterioration in patients with MS., ${ }^{3,4}$ Widespread axonal damage and the resulting disconnection of neuronal circuits has also a prominent role in the pathogenesis of fatigue and affective symptoms such as depression. ${ }^{5,6}$ Yet, in standard clinical care, accurate and regular cognitive and neuropsychiatric assessment is often not incorporated despite its clinical importance due to limited time and financial resources. ${ }^{7}$ Disease activity and burden is instead approached by traditional measures such as the Expanded Disability Status Scale (EDSS), the Multiple Sclerosis Severity Score, or the Multiple Sclerosis Functional Composite, which do not sufficiently mirror cognitive and neuropsychiatric status. New biomarkers are therefore needed that easily and sensitively assess tissue damage at the axonal level and thereby might predict clinically relevant outcomes such as cognition, fatigue, and mood disturbances.

Neurofilament light chain (NfL) is a promising molecular surrogate marker that indicates neuroaxonal injury in various diseases because it is released into CSF and blood as a subunit of a cytoskeletal protein in case of neuroaxonal damage. ${ }^{8,9}$ In MS, CSF NfL levels correlate with classical relapses and disability. ${ }^{10-12}$ Recently, the single molecule array (Simoa) immunoassay technology ${ }^{13}$ with unprecedented analytical sensitivity enabled the detection of subtle NfL levels even in serum samples ${ }^{14}$ and successfully linked serum NfL ( $\mathrm{sNfL}$ ) to neuroaxonal damage and therapy effects in MS. ${ }^{15,16}$ Few studies though specifically explored $\mathrm{NfL}$ as a biomarker of cognitive performance and fatigue in MS. ${ }^{17-22}$ Importantly, most of them measured NfL levels in CSF, although studies on sNfL levels and cognition, fatigue, depression, or anxiety are rare.

Here, we investigated whether we could confirm previous results relating CSF NfL and cognitive performance in MS by sNfL testing. We additionally examined whether sNfL is related to fatigue, depression, and anxiety in our sample of patients with MS with mild clinical deficits.

\section{Methods}

\section{Patient population}

We consecutively recruited patients with RRMS and SPMS from local ambulatory settings during October 2016September 2018. All patients had a confirmed MS diagnosis according to the revised McDonald 2010 criteria, had an EDSS score of $\leq 5.0$, were aged between 18 and 60 years, were fluent in German language, and were free of relapses for at least the past 60 days. Diagnoses and disease courses were documented in patients' most recent medical records by their referring neurologists and were all reviewed and verified by the authors (O.A. and A.R.). Patients were required to present at least with mild CI, defined as a Symbol Digit Modalities Test (SDMT) $z$ score of $\leq-0.5$ and $>-3.0$, which was confirmed during the neuropsychological assessment. Exclusion criteria covered any acute neurologic (other than MS), systemic inflammatory, oncologic, or psychiatric condition, severe visual or hearing impairment not otherwise corrected, or upper extremity deficits that could interfere with neuropsychological testing performance. The final sample consisted of 45 patients.

\section{Neuropsychological assessment and procedures}

Demographical and clinical information was sampled by a trained neuropsychologist. Table 1 displays the cognitive tests and self-report questionnaires comprised in subsequent neuropsychological testing. Two psychologists doublechecked data transfer from paper record sheets into electronical databases to avoid data entry errors and to ensure data quality.

\section{Neurologic assessment, MRI, and measurement of sNfL}

A clinical visit for standard neurologic examinations, MRI scanning, and blood sampling all in 1 day was scheduled in the context of the neuropsychological assessment, and most participants were seen within 4 weeks. A certified neurologist of the Department of Neurology scored each participant on the EDSS according to established standards. ${ }^{23}$ In a 3T MRI system (Siemens Skyra, Erlangen, Germany), we acquired sagittal T1-weighted sequences (magnetization-prepared rapid acquisition with gradient echo [MPRAGE]) with $1 \mathrm{~mm}$ isotropic resolution (repetition time $[\mathrm{TR}]=2,300 \mathrm{~ms}$, echo time $[\mathrm{TE}]=$ $2.98 \mathrm{~ms}$, field of view $[\mathrm{FoV}]=256 \times 256 \mathrm{~mm}$, and 192 slices) and sagittal fluid-attenuated inversion recovery sequences with 
Table 1 Neuropsychological assessment

\begin{tabular}{|c|c|}
\hline Domain & Test/questionnaire \\
\hline \multirow[t]{2}{*}{ Information processing speed } & $\mathrm{SDMT}^{\mathrm{a}}$ \\
\hline & TMT-A \\
\hline \multirow[t]{4}{*}{ Short-term memory and learning } & VLMT direct recalla \\
\hline & BVMT-R direct recall ${ }^{\mathrm{a}}$ \\
\hline & Digit span forward \\
\hline & Corsi block forward \\
\hline \multirow[t]{4}{*}{ Long-term memory } & VLMT delayed recall \\
\hline & VLMT recognition \\
\hline & BVMT-R delayed recall \\
\hline & BVMT-R recognition \\
\hline \multirow[t]{2}{*}{ Working memory } & Digit span backward \\
\hline & Corsi block backward \\
\hline \multirow[t]{2}{*}{ Verbal fluency } & RWT phonetic condition \\
\hline & RWT semantic condition \\
\hline \multirow[t]{3}{*}{ Executive functions } & TMT-B \\
\hline & RWT switching condition \\
\hline & DKEFS TAS ${ }^{b}$ \\
\hline Subjective cognitive problems & PDQ-20 \\
\hline Fatigue & FSMC \\
\hline Anxiety & HADS A \\
\hline Depression & HADS D \\
\hline \multicolumn{2}{|c|}{$\begin{array}{l}\text { Abbreviations: BVMT-R = Brief Visuospatial Memory Test-Revised; DKEFS } \\
\text { TAS = Delis-Kaplan Executive Function System Tower Test Total Achieve- } \\
\text { ment Score; FSMC = Fatigue Scale for Motor and Cognitive Functions; } \\
\text { HADS = Hospital Anxiety and Depression Scale; PDQ-20 = Perceived Deficit } \\
\text { Questionnaire; RRMS = relapsing-remitting MS; RWT = Regensburger } \\
\text { Verbal Fluency Test; SDMT = Symbol Digit Modalities Test; SPMS = secondary } \\
\text { progressive MS; TMT = Trail Making Test; VLMT = Verbaler Lern- und } \\
\text { Merkfaehigkeitstest. } \\
\text { a Components of Brief International Cognitive Assessment for MS. } \\
\text { b Missing data on DKEFS TAS for } 12 \text { patients with RRMS and } 2 \text { patients with } \\
\text { SPMS. }\end{array}$} \\
\hline
\end{tabular}

$1 \mathrm{~mm}^{3}$ resolution $(\mathrm{TR}=5,000 \mathrm{~ms}, \mathrm{TE}=386.00 \mathrm{~ms}, \mathrm{FoV}=256$ $\times 256 \mathrm{~mm}$, and 192 slices). T2 lesion load (T2-LL) was assessed by using the SPM lesion segmentation toolbox (Label Propagation algorithm ${ }^{24}$ ). After lesion filling with the FMRIB Software Library (FSL ${ }^{25}$ ) lesion filling toolbox, normalized brain volume (NBV), cortical brain volume (CBV), and deep gray matter volume (DGV) were assessed from MPRAGE images using SIENAX (FSL).

Serum samples were labeled following a pseudonymized algorithm (4-eye principle for the encoding) and stored at $-80^{\circ} \mathrm{C}$ before blinded evaluation. Samples were shipped on dry ice to the Department of Neurology, University Hospital of Ulm, where sNfL concentrations were determined by digital immunoassay using the Simoa NF-light Advantage Kit (Quanterix Corporation, Lexington, MA) on our previously described setup. ${ }^{26}$ Preparation of samples including dilution steps was performed according to the manufacturer's instructions, and $\mathrm{NfL}$ levels were determined in duplicates, using the corresponding standard curve. The intra-assay coefficient of variation (CV) was assessed by measuring a quality control serum, with a resulting $\mathrm{CV}$ below $5 \%$. We accepted results of duplicates as valid if the $\mathrm{CV}$ of both measurements was below $20 \%$, which was true for all samples.

\section{Statistical analysis}

Cognitive performances below the fifth percentile according to each test's manual were identified as impaired. Global CI was defined as impairment in at least 2 cognitive domains. Performance in the Brief International Cognitive Assessment for MS (BICAMS) battery was considered impaired if at least 1 subtest score was below the fifth percentile. ${ }^{27}$

We first examined the relationships of sNfL levels with demographical, clinical, imaging parameters, cognitive, and patient-reported outcomes by Pearson's correlation coefficient or Spearman's rank correlation. Whether sNfL levels differ along with categorical variables (sex and $\mathrm{CI}$ ) was examined through group comparisons. Partial correlations were calculated to adjust for potential subtype effects. In a next step, 2 groups (low and high sNfL based on median split) were separated and compared on their performance in each test and questionnaire, as well as on global CI, and other demographical and clinical parameters using Student $t$ tests or the Fisher exact test for parametric and using Mann-Whitney $U$ tests for nonparametric variables. Group comparisons were also controlled for age, educational level, sex, and MS subtype using analyses of covariance. Finally, we conducted linear regression analyses with test and questionnaire scores, as well as the number of impaired cognitive tests and domains as the dependent and sNfL as the independent variable. Logistic regression models were analyzed likewise to predict impairment in each cognitive and affective domain including fatigue, impairment in BICAMS, and global CI. In all models, age, educational level, sex, and MS subtype were entered as covariates. In addition, outliers with standardized residuals $>3$ or $<-3$ were excluded from the analyses. Despite being clearly aware that the subsample sizes of patients with RRMS vs SPMS in this work are not appropriate to draw general conclusions, we conducted separate correlational analyses as described previously in the 2 disease subtypes. We therefore aimed at exploring whether there are potential differences in the association of sNfL with demographical, clinical, cognitive, and neuropsychiatric parameters according to the MS phenotype.

Analyses were performed with IBM SPSS 25, with a significance threshold set at $p=0.05$. 
Table 2 Main demographical and clinical characteristics

\begin{tabular}{|c|c|}
\hline Variable & Total sample $(\mathrm{N}=45)$ \\
\hline Age, y, mean $\pm S D$ (median; range; IQR) & $45.63 \pm 10.53(47.61 ; 18.06-60.11 ; 16.49)$ \\
\hline Sex, female, $n(\%)$ & $39(86.7)$ \\
\hline \multicolumn{2}{|l|}{ Education, $\mathbf{n}(\%)$} \\
\hline Low & $4(8.9)$ \\
\hline Middle & $9(20.0)$ \\
\hline High & $32(71.1)$ \\
\hline \multicolumn{2}{|l|}{ Disease course, $\mathbf{n}(\%)$} \\
\hline RRMS & $38(84.4)$ \\
\hline SPMS & $7(15.6)$ \\
\hline Age at onset, $y$, mean \pm SD (median; range; IQR) & $35.10 \pm 9.87(35.97 ; 14.94-53.19 ; 15.5)$ \\
\hline Disease duration, $y$, mean \pm SD (median; range; IQR) & $10.03 \pm 7.49(8.08 ; 0.51-28.27 ; 12.20)$ \\
\hline EDSS, mean \pm SD (median; range; IQR) & $2.73 \pm 1.12(3 ; 0-5 ; 1.5)$ \\
\hline \multicolumn{2}{|l|}{ Immunotherapy classification, $\mathrm{n}(\%)$} \\
\hline None & $7(15.6)$ \\
\hline First line & $24(53.3)$ \\
\hline Second line & $14(31.1)$ \\
\hline Time since last relapse, mo, mean $\pm S D$ (median; range; IQR) ${ }^{a}$ & $37.91 \pm 40.97(21.84 ; 2.89-158.85 ; 41.33)$ \\
\hline Time since last immunotherapy change, mo, mean $\pm S D$ (median; range; IQR) & $40.65 \pm 47.86(24.89 ; 1.86-220.06 ; 41.22)$ \\
\hline $\mathrm{T} 2-\mathrm{LL}, \mathrm{cm}^{3}$, mean $\pm \mathrm{SD}$ (median; range; IQR) ${ }^{\mathrm{b}}$ & $10.17 \pm 10.18(5.97 ; 0.99-36.43 ; 11.75)$ \\
\hline $\mathrm{NBV}, \mathrm{cm}^{3}$, mean $\pm \mathrm{SD}\left(\right.$ median; range; IQR) ${ }^{\mathrm{b}}$ & $1,441.92 \pm 69.41(1,455.23 ; 1,256.01-1,554.36 ; 111.45)$ \\
\hline $\mathrm{CBV}, \mathrm{cm}^{3}$, mean $\pm \mathrm{SD}$ (median; range; IQR) & $591.15 \pm 37.16(591.77 ; 517.37-687.93 ; 45.14)$ \\
\hline DGV, $\mathrm{cm}^{3}$, mean \pm SD (median; range; IQR) & $42.31 \pm 6.29(42.78 ; 24.98-53.02 ; 8.17)$ \\
\hline $\mathrm{sNfL}, \mathrm{pg} / \mathrm{mL}$, mean $\pm \mathrm{SD}$ (median; range; IQR) & $16.02 \pm 10.39(13.8 ; 4.55-51.6 ; 11.98)$ \\
\hline BICAMS impaired, $\mathbf{n}(\%)$ & $18(40.0)$ \\
\hline Global Cl, n (\%) & $28(62.2)$ \\
\hline
\end{tabular}

Abbreviations: BICAMS = Brief International Cognitive Assessment for MS; CBV = cortical brain volume; $\mathrm{Cl}=$ cognitive impairment; $\mathrm{DGV}=$ deep gray matter volume; EDSS = Expanded Disability Status Scale; educational level low $=\leq 10$ years, medium $=11$ years, and high $=\geq 12$ years; first-line medication $=$ induction approach drug (moderate efficacy, high safety), incl. interferon- $\beta(n=4)$, glatiramer acetate $(n=6)$, dimethyl fumarate $(n=13)$, and cyclophosphamide $(n=1)$; $\mathrm{IQR}=$ interquartile range; NBV = normalized brain volume; RRMS = relapsing-remitting MS; second-line medication = escalation approach drug (high efficacy, more safety risks), incl. natalizumab $(n=5)$, fingolimod $(n=6)$, alemtuzumab $(n=1)$, rituximab $(n=1)$, and daclizumab $(n=1)$; sNfL= serum neurofilament light; SPMS = secondary progressive MS; T2-LL = lesion load.

${ }^{\text {a }}$ Missing information on time since last relapse for 1 patient with SPMS.

${ }^{\mathrm{b}}$ Missing information on lesion load, normalized brain volume, and cortical brain volume for 1 patient with RRMS.

\section{Standard protocol approvals, registrations, and patient consents}

All patients participated voluntarily in the study and provided written informed consent. The study was approved by the Ethics Committee of the Heinrich Heine University (study number: 5531R, registration-ID: 2016055083) and was conducted in accordance with the principles of the Declaration of Helsinki.

\section{Data availability}

Anonymized data will be made available by the corresponding author on reasonable request from any qualified investigator.

\section{Results}

\section{Patient and sNfL characteristics}

Demographical and clinical characteristics of the final sample are shown in table 2. Importantly, no participant experienced a relapse or changed immunomodulatory treatment within the past 2 months before blood sampling. The mean EDSS score was 2.73 (RRMS: mean $=2.62[\mathrm{SD}=1.09]$, SPMS: mean $=3.36[\mathrm{SD}=1.18] ; t(43)=-1.63, p=0.110, r=0.242)$, while EDSS data of the total sample were distributed unimodally and without any outliers. T2-LL (RRMS: median = 
Table 3 Correlations between sNfL levels and demographical and clinical parameters

\begin{tabular}{|c|c|c|c|c|}
\hline & \multicolumn{4}{|l|}{ sNfL } \\
\hline & \multicolumn{2}{|c|}{ RRMS ( $n=38)$} & \multicolumn{2}{|c|}{ SPMS $(n=7)$} \\
\hline & $r$ & $p$ Value & $r$ & $p$ Value \\
\hline Age, y & 0.216 & 0.194 & -0.126 & 0.789 \\
\hline Educational level & -0.163 & 0.329 & -0.316 & 0.490 \\
\hline Disease duration, y & 0.291 & 0.077 & 0.139 & 0.766 \\
\hline Age at disease onset, $y$ & 0.046 & 0.785 & -0.135 & 0.773 \\
\hline EDSS & 0.124 & 0.457 & -0.019 & 0.968 \\
\hline Immunomodulatory treatment classification & 0.109 & 0.516 & 0.144 & 0.758 \\
\hline Time since last relapse, mo & -0.017 & 0.921 & 0.531 & 0.279 \\
\hline Time since last change in DMT, mo & 0.084 & 0.631 & 0.802 & 0.407 \\
\hline T2-LL, $\mathrm{cm}^{3}$ & 0.305 & 0.067 & 0.180 & 0.700 \\
\hline $\mathrm{NBV}, \mathrm{cm}^{3}$ & -0.229 & 0.172 & -0.229 & 0.622 \\
\hline $\mathrm{CBV}, \mathrm{cm}^{3}$ & -0.262 & 0.117 & -0.408 & 0.363 \\
\hline $\mathrm{DGV}, \mathrm{cm}^{3}$ & -0.191 & 0.250 & -0.485 & 0.270 \\
\hline
\end{tabular}

Abbreviations: $\mathrm{CBV}$ = cortical brain volume; DGV = deep gray matter volume; $\mathrm{EDSS}=$ Expanded Disability Status Scale; NBV = normalized brain volume; RRMS = relapsing-remitting MS; SNfL = serum neurofilament light; SPMS = secondary progressive MS; T2-LL = lesion load.

Reported are Pearson's correlation coefficients (combination with interval variable) or Spearman's rank correlation (association with ordinal variable).

$6.06 \mathrm{~cm}^{3}$, SPMS: median $=5.89 \mathrm{~cm}^{3}, U=116.00, p=0.683, r$ $=-0.065$ ), NBV (RRMS: mean $=1,443.29 \mathrm{~cm}^{3}[\mathrm{SD}=72.33]$, SPMS: mean $=1,434.64 \mathrm{~cm}^{3}[\mathrm{SD}=55.41] ; t(42)=0.30$, $p=0.766, r=0.046), \mathrm{CBV}\left(\mathrm{RRMS}:\right.$ mean $=592.00 \mathrm{~cm}^{3}[\mathrm{SD}=$ 40.23], SPMS: mean $=586.66 \mathrm{~cm}^{3}[\mathrm{SD}=12.48] ; t(32.11)=$ $0.66, p=0.516, r=0.115$ ), and DGV (RRMS: median $=43.31$ $\mathrm{cm}^{3}$, SPMS: median $=41.53 \mathrm{~cm}^{3}, U=99.00, p=0.301, r=$ -0.159) did not differ between patients with RRMS and SPMS. CI according to the BICAMS battery was present in $40 \%$ of all participants (RRMS: $42.1 \%$, SPMS: $28.6 \%$; $p=$ 0.684 using the Fisher exact test, $r=0.100$ ) and in accordance with the definition of global CI in $62.2 \%$ of the total sample (RRMS: $65.8 \%$, SPMS: 42.9\%; $p=0.399$ using the Fisher exact test, $r=0.171)$. The mean sNfL level was $16.02 \mathrm{pg} / \mathrm{mL}$, with higher levels in patients with SPMS (RRMS: median = $12.00 \mathrm{pg} / \mathrm{mL}$, SPMS: median $=20.00 \mathrm{pg} / \mathrm{mL} ; U=67.0, p=$ $0.038, r=-0.308)$.

\section{Association of sNfL levels with demographical and clinical parameters}

We did not find any correlation between sNfL and age, sex, educational level, EDSS score, age at disease onset, subtype, immunotherapy classification, time since last relapse, time since last change in immunomodulatory treatment, T2-LL, NBV, CBV, or DGV in each subsample (RRMS and SPMS) separately (table 3 ). In partial correlation analyses of the total sample adjusting for the MS subtype, we observed a tentative relationship with disease duration $\left(r_{p}=0.272, p=\right.$ $0.074)$, T2-LL $\left(r_{p}=0.285, p=0.064\right)$, and CBV $\left(r_{p}=-0.260\right.$, $p=0.093)$.
When comparing patients with low sNfL values to patients with high sNfL values, groups differed with respect to DGV, meaning that patients with high sNfL values had lower DGV. Taking effect sizes into consideration, associations were also indicated for CBV, age, and disease duration (table 5). We observed no other notable difference between patients with low $\mathrm{sNfL}$ values compared to high sNfL values with respect to all other demographical and clinical variables.

\section{Association of sNfL levels with cognition and neuropsychiatric parameters}

In the RRMS sample, sNfL levels did correlate neither significantly with any of the investigated cognitive performance measures or self-report questionnaires on fatigue, depression, and anxiety nor with the number of impaired tests or impaired domains. With reference to effect sizes, $\mathrm{sNfL}$ is suggested to relate with SDMT performance albeit not reaching significance (see table 4 for detailed results). We did not find differences in sNfL levels related to CI in BICAMS (not impaired: median $=12.00$ $\mathrm{pg} / \mathrm{mL}$, impaired: median $=12.40 \mathrm{pg} / \mathrm{mL}, U=154.00, p=$ $0.529, r=-0.106)$ and in the overall test battery (not impaired: median $=10.40 \mathrm{pg} / \mathrm{mL}$, impaired: median $=13.80 \mathrm{pg} / \mathrm{mL}, U=$ $140.00, p=0.504, r=-0.112$ ). The same applies to the subgroup of 7 patients with SPMS for BICAMS (not impaired: median = $19.50 \mathrm{pg} / \mathrm{mL}$, impaired: median $=29.40 \mathrm{pg} / \mathrm{mL}, U=2.00, p=$ $0.381, r=-0.609$ ) and the overall test battery (not impaired: median $=18.40 \mathrm{pg} / \mathrm{mL}$, impaired: median $=20.00 \mathrm{pg} / \mathrm{mL}, U=$ 5.00, $p=0.857, r=-0.134)$. We observed, however, negative correlations with the Brief Visuospatial Memory Test-Revised (BVMT-R) direct recall, BVMT-R delayed recall, and Delis- 
Table 4 Correlations between sNfL levels and neuropsychological parameters

\begin{tabular}{|c|c|c|c|c|}
\hline & \multicolumn{4}{|l|}{ sNfL } \\
\hline & \multicolumn{2}{|c|}{ RRMS ( $n=38)$} & \multicolumn{2}{|c|}{ SPMS $(n=7)$} \\
\hline & $r$ & $p$ Value & $r$ & $p$ Value \\
\hline \multicolumn{5}{|l|}{ Cognitive test scores } \\
\hline SDMT & -0.296 & 0.071 & 0.320 & 0.484 \\
\hline VLMT direct recall & -0.106 & 0.526 & 0.023 & 0.962 \\
\hline VLMT delayed recall & -0.126 & 0.452 & 0.113 & 0.809 \\
\hline VLMT recognition & 0.072 & 0.668 & 0.122 & 0.794 \\
\hline BVMT-R direct recall & -0.214 & 0.197 & -0.950 & $0.001 * *$ \\
\hline BVMT-R delayed recall & -0.228 & 0.169 & -0.813 & $0.026^{*}$ \\
\hline BVMT-R recognition & 0.087 & 0.604 & -0.742 & 0.056 \\
\hline TMT-A & 0.094 & 0.368 & -0.075 & 0.872 \\
\hline TMT-B & 0.120 & 0.415 & -0.245 & 0.597 \\
\hline Digit span forward & 0.150 & 0.969 & 0.247 & 0.593 \\
\hline Digit span backward & -0.136 & 0.309 & 0.035 & 0.941 \\
\hline Block span forward & -0.006 & 0.574 & 0.395 & 0.381 \\
\hline Block span backward & -0.170 & 0.472 & 0.416 & 0.353 \\
\hline RWT phonetic & 0.079 & 0.636 & 0.160 & 0.732 \\
\hline RWT semantic & -0.036 & 0.830 & 0.155 & 0.740 \\
\hline RWT switching & 0.045 & 0.789 & 0.087 & 0.853 \\
\hline DKEFS TAS & -0.191 & 0.350 & -0.901 & $0.037^{*}$ \\
\hline No. of impaired tests & -0.044 & 0.793 & 0.327 & 0.474 \\
\hline No. of impaired domains & -0.060 & 0.721 & 0.327 & 0.474 \\
\hline \multicolumn{5}{|l|}{ Questionnaires } \\
\hline FSMC total & -0.051 & 0.763 & -0.562 & 0.189 \\
\hline HADS A & -0.185 & 0.267 & -0.526 & 0.225 \\
\hline HADS D & 0.012 & 0.941 & -0.410 & 0.361 \\
\hline PDQ-20 total & -0.044 & 0.791 & -0.499 & 0.254 \\
\hline \multicolumn{5}{|c|}{$\begin{array}{l}\text { Abbreviations: BVMT-R = Brief Visuospatial Memory Test-Revised; DKEFS TAS = Delis-Kaplan Executive Function System Tower Test Total Achievement } \\
\text { Score; FSMC = Fatigue Scale for Motor and Cognitive Functions; HADS = Hospital Anxiety and Depression Scale; PDQ-20 = Perceived Deficit Questionnaire; } \\
\text { RRMS = relapsing-remitting MS; RWT = Regensburger Verbal Fluency Test; SNfL = serum neurofilament light; SDMT = Symbol Digit Modalities Test; SPMS = } \\
\text { secondary progressive MS; TMT = Trail Making Test; VLMT = Verbaler Lern- und Merkfaehigkeitstest. } \\
\text { Reported are Pearson's correlation coefficients. Interpretation of } p \text { values: }{ }^{*} p<0.05 \text { and } \star \star \star x<0.01 .\end{array}$} \\
\hline
\end{tabular}

Kaplan Executive Function System Tower Test Total Achievement Score in this subtype (see table 4 for detailed statistics).

When adjusting correlations in the total sample for MS subtype, we still found a negative relation between $\mathrm{sNfL}$ levels and BVMT-R performance with a moderate effect size, although not significant (direct recall: $r_{p}=-0.285, p=0.060$; delayed recall: $\left.r_{p}=-0.283, p=0.062\right)$. When adjusting correlations for further variables that potentially influence cognitive performance (age, educational level, sex, and subtype), correlation coefficients diminished and none of the examined relationships turned out significant.

In the total sample, patients with high sNfL levels performed worse on the BVMT-R delayed recall (and direct recall by tendency) than patients with low sNfL levels (table 5). Despite considerable effect sizes, group differences according to sNfL status were no longer detectable when controlling for variables potentially influencing cognitive performance (age, sex, educational level, and subtype). 
Table 5 Demographics and neuropsychological test scores of patients with low and high sNfL levels (mean \pm SD [range]; or percentages for $\mathrm{Cl}$ frequencies)

\begin{tabular}{|c|c|c|c|c|}
\hline Variable & Low sNfL $(n=22)$ & High sNfL $(n=23)$ & $p$ Value & $r$ \\
\hline \multicolumn{5}{|l|}{ Demographics (selected) } \\
\hline Age, y & $43.37 \pm 10.03(26.74-57.73)$ & $47.80 \pm 10.77(18.06-60.11)$ & 0.069 & -0.270 \\
\hline Disease duration, $y$ & $7.71 \pm 5.75(0.51-20.86)$ & $12.25 \pm 8.37(0.79-28.27)$ & 0.084 & -0.257 \\
\hline EDSS & $2.70 \pm 0.97(1-4)$ & $2.76 \pm 1.27(0-5)$ & 0.817 & -0.035 \\
\hline $\mathrm{T} 2-\mathrm{LL}, \mathrm{cm}^{3}$ & $7.67 \pm 8.44(0.99-35.21)$ & $12.66 \pm 11.31(1.21-36.43)$ & 0.127 & -0.230 \\
\hline $\mathrm{NBV}, \mathrm{cm}^{3}$ & $1,458.05 \pm 72.51(1,256.01-1,554.36)$ & $1,425.78 \pm 63.74(1,303.04-1,503.66)$ & 0.124 & 0.235 \\
\hline CBV, $\mathrm{cm}^{3}$ & $600.73 \pm 39.05(517.37-687.93)$ & $581.58 \pm 33.32(525.68-645.16)$ & 0.087 & 0.261 \\
\hline $\mathrm{DGV}, \mathrm{cm}^{3}$ & $43.62 \pm 6.88(24.98-53.02)$ & $41.06 \pm 5.52(28.83-51.74)$ & $0.048 *$ & -0.294 \\
\hline \multicolumn{5}{|l|}{ Cognitive test scores } \\
\hline SDMT & $44.68 \pm 8.22(24-58)$ & $41.74 \pm 8.76(26-61)$ & 0.252 & 0.174 \\
\hline VLMT direct recall & $56.50 \pm 10.80(27-73)$ & $51.43 \pm 11.49(23-70)$ & 0.135 & 0.226 \\
\hline VLMT delayed recall & $11.50 \pm 3.17(3-15)$ & $10.70 \pm 3.20(2-15)$ & 0.302 & -0.154 \\
\hline VLMT recognition & $13.18 \pm 2.13(9-15)$ & $12.65 \pm 2.39(8-15)$ & 0.326 & -0.146 \\
\hline BVMT-R direct recall & $24.27 \pm 5.88(12-34)$ & $20.61 \pm 7.88(2-34)$ & 0.085 & 0.259 \\
\hline BVMT-R delayed recall & $9.73 \pm 2.88(2-12)$ & $8.13 \pm 3.21(0-12)$ & $0.029 *$ & -0.326 \\
\hline BVMT-R recognition & $5.45 \pm 1.34(0-6)$ & $5.09 \pm 2.04(-1$ to 6$)$ & 0.849 & 0.028 \\
\hline TMT-A & $37.75 \pm 15.21(18.65-90.74)$ & $42.60 \pm 14.20(25.08-82.24)$ & 0.200 & -0.191 \\
\hline TMT-B & $84.30 \pm 30.71(33.53-168.94)$ & $98.49 \pm 50.50(40.29-256.78)$ & 0.467 & -0.108 \\
\hline Digit span forward & $7.05 \pm 2.01(3-11)$ & $7.57 \pm 1.67(4-10)$ & 0.278 & -0.162 \\
\hline Digit span backward & $7.18 \pm 1.97(2-10)$ & $6.39 \pm 1.70(3-9)$ & 0.127 & -0.228 \\
\hline Block span forward & $8.36 \pm 1.62(5-11)$ & $8.48 \pm 1.62(6-12)$ & 0.835 & -0.031 \\
\hline Block span backward & $7.59 \pm 1.97(4-11)$ & $7.74 \pm 2.12(2-11)$ & 0.730 & -0.051 \\
\hline RWT phonetic & $19.32 \pm 5.68(5-28)$ & $19.17 \pm 9.10(4-37)$ & 0.937 & -0.012 \\
\hline RWT semantic & $31.59 \pm 7.62(14-41)$ & $28.91 \pm 9.74(12-42)$ & 0.488 & -0.103 \\
\hline RWT switching & $20.82 \pm 4.00(11-29)$ & $20.61 \pm 4.65(12-28)$ & 0.964 & -0.007 \\
\hline DKEFS TAS & $19.36 \pm 3.37(13-25)$ & $17.35 \pm 3.84(12-23)$ & 0.175 & -0.202 \\
\hline No. of impaired tests & $2.68 \pm 2.98(0-9)$ & $3.00 \pm 2.63(0-11)$ & 0.363 & -0.136 \\
\hline No. of impaired domains & $1.91 \pm 1.82(0-6)$ & $2.22 \pm 1.45(0.5)$ & 0.312 & -0.151 \\
\hline BICAMS CI & $36.36 \%$ & $43.48 \%$ & 0.763 & 0.073 \\
\hline Global CI & $54.55 \%$ & $69.57 \%$ & 0.365 & 0.155 \\
\hline \multicolumn{5}{|l|}{ Questionnaires } \\
\hline FSMC total & $72.32 \pm 12.76(50-97)$ & $70.23 \pm 14.47(36-87)$ & 0.829 & -0.032 \\
\hline HADS A & $7.86 \pm 3.58(1-15)$ & $6.48 \pm 3.67(2-16)$ & 0.154 & -0.213 \\
\hline HADS D & $5.82 \pm 4.50(1-15)$ & $5.78 \pm 4.35(0-15)$ & 0.945 & -0.010 \\
\hline PDQ-20 total & $31.27 \pm 12.94(5-53)$ & $31.74 \pm 12.16(10-57)$ & 0.946 & -0.010 \\
\hline
\end{tabular}

Abbreviations: BICAMS = Brief International Cognitive Assessment for MS; BVMT-R = Brief Visuospatial Memory Test - Revised; $C B V=$ cortical brain volume; $\mathrm{Cl}$ = cognitive impairment; DGV = deep gray matter volume; DKEFS TAS = Delis-Kaplan Executive Function System Tower Test Total Achievement Score; EDSS = Expanded Disability Status Scale; FSMC = Fatigue Scale for Motor and Cognitive Functions; HADS = Hospital Anxiety and Depression Scale; NBV = normalized brain volume; PDQ-20 = Perceived Deficit Questionnaire; RWT = Regensburger Verbal Fluency Test; sNfL = serum neurofilament light; SDMT = Symbol Digit Modalities Test; T2-LL = lesion load; TMT = Trail Making Test; VLMT = Verbaler Lern- und Merkfaehigkeitstest.

Reported are results of Student $t$ tests, Mann-Whitney $U$ tests, and the Fisher exact test. Interpretation of $p$ values: ${ }^{*} p<0.05$; $r=$ correlation coefficient as effect size measure. 

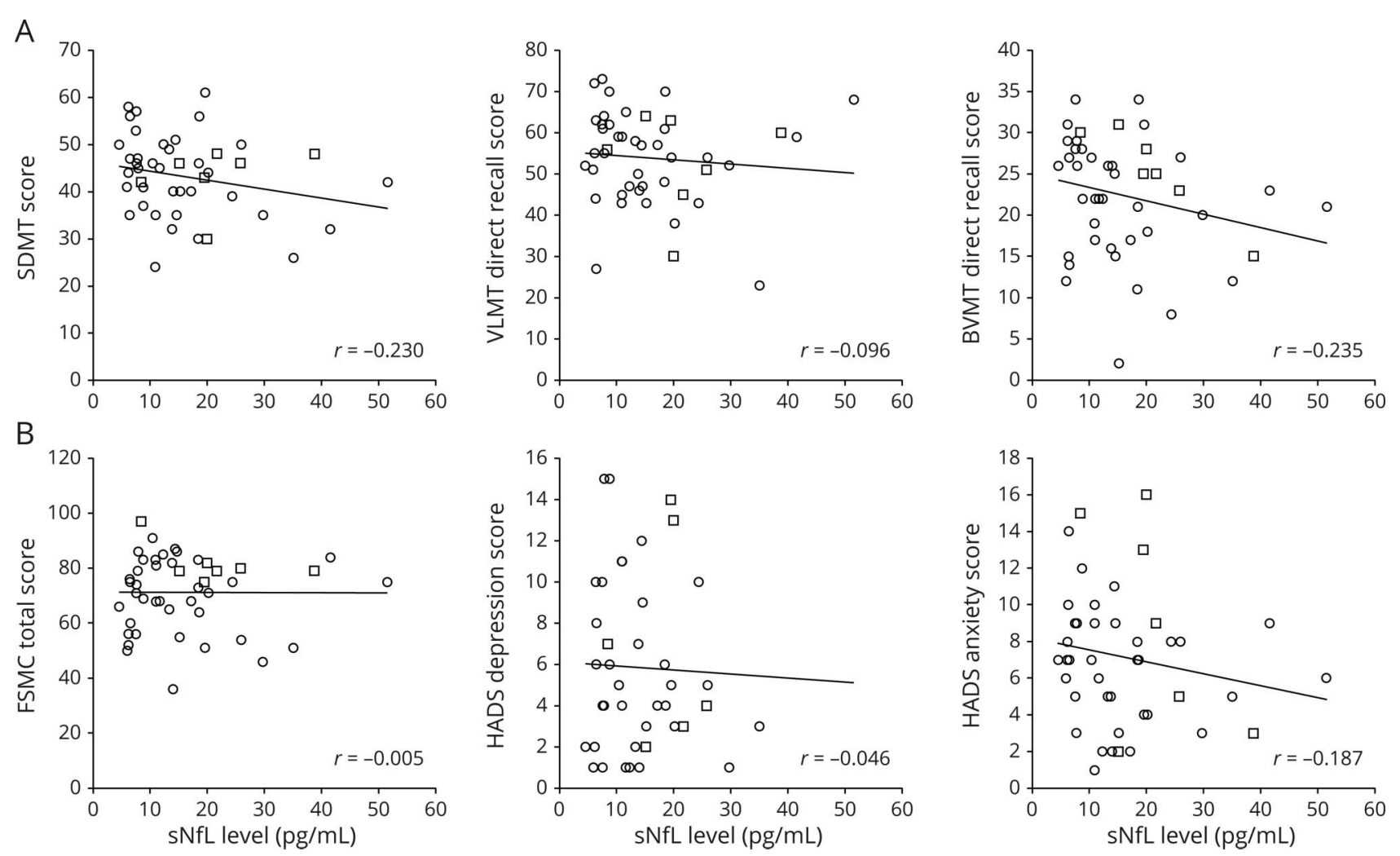

Row A: single tests of the Brief International Cognitive Assessment for MS battery. Row B: fatigue, depression, and anxiety questionnaire scores. Circled data points stem from patients with relapsing-remitting MS and squared data points from patients with secondary progressive MS. Included regression lines and correlation coefficients refer to the total sample's data. BVMT-R = Brief Visuospatial Memory Test-Revised; FSMC = Fatigue Scale for Motor and Cognitive Functions; HADS = Hospital Anxiety and Depression Scale; SDMT = Symbol Digit Modalities Test; sNfL = serum neurofilament light chain; VLMT = Verbaler Lern- und Merkfaehigkeitstest.

Finally, in the regression analyses, sNfL did not predict cognitive performance, fatigue, depression, or anxiety levels (neither the continuous performance scores in linear models nor categorical impairment in logistic models) (figure).

\section{Discussion}

In this study, we investigated whether and how sNfL levels are associated with cognitive and neuropsychiatric status in patients with MS.

In the examined group of patients with RRMS and SPMS, sNfL levels were comparable with previous studies using the same methodology, ${ }^{26,28}$ supporting the reliability of our results and of the applied assay analysis method. The observed prevalence rate of CI of $40 \%$ according to BICAMS and $62.2 \%$ when considering all assessed domains in this study also matches with former investigations. ${ }^{29,30}$ Notably, these percentages might have been overestimated because of the inclusion criteria of an SDMT scoring of at least $z \leq-0.5$. Mean performance scores of other tests (for instance of Verbaler Lern- und Merkfaehigkeitstest and BVMT-R) were average compared with normative values, albeit our sample was heterogeneously distributed considering demographical variables (such as age and educational level) to resemble patient populations in reallife settings. Patients with SPMS moreover did not differ from patients with RRMS in any of the cognitive test scores (details not reported), altogether suggesting that this sample's cognitive functions were only mildly to moderately affected. The same can be noted for physical disability, as patients' mean EDSS score was less than 3 (with maximum values not greater than 5) and did not differ between RRMS and SPMS. It can be presumed that only patients with relatively preserved clinical functioning, feeling capable of bearing a comprehensive testing, and making their way autonomously to and between the test centers registered for the study. Our MRI data compared with data from studies that particularly examined patients at higher functioning levels (i.e., patients with minimal physical disability or without CI) finally support the assumption that our sample has not been exposed to high neuronal disease activity on average. $^{31,32}$

Regarding demographical and clinical variables, we found sNfL to relate by tendency with age, disease duration, and imaging measures of lesion load and brain atrophy (T2-LL, $\mathrm{CBV}$, and DGV). This agrees with the idea of sNfL potentially indicating axonal damage and neuronal degeneration in 
accordance with other numerous studies, ${ }^{15}$ although effect sizes were rather small.

Regarding cognitive performance and neuropsychiatric measures, sNfL was only related to visuospatial learning and memory. This seems to be mainly driven by patients with SPMS because correlational analyses in separate MS subtypes were significant only in this subgroup. These results align with a recent study that also examined BICAMS (with NfL from CSF) and observed the only domain-specific, tentative relation between NfL and BVMT-R performance. Besides, the authors did not find an association of BICAMS test performance within the subgroup of patients with RRMS as opposed to progressive patients. They argued that this might be traced to greater gray matter degeneration, expressed in higher Nfl levels, in the progressive subtype ${ }^{19}$ Visuospatial learning and memory were indeed defined within 1 cognitive cluster along with information processing speed, both being frequently and severely affected in the course of the disease and thus constituting sensitive domains for cognitive screening, particularly in SPMS. $^{33,34}$ Other studies correspondingly observed information processing speed to be linked with NfL derived from plasma, ${ }^{35} \mathrm{CSF},{ }^{17,18}$ and serum. ${ }^{36}$ Despite approaching a medium effect size, this association did not reach significance in our sample though. Jakimovski et al. ${ }^{36}$ for instance specifically measured sNfL with the same technique as in this study. They found sNfL to correlate with information processing speed in a considerably mixed sample of patients with relapsing and progressive MS, but not in patients with clinically isolated syndrome (CIS).

The results within the subsample of patients with SPMS in our study should be interpreted with caution because of the very small group size that potentially has biased statistical analyses and effect size estimations. In parallel, the overall sample size entails risk for lacking power in trying to detect associations between sNfL and demographical, clinical, cognitive, or neuropsychiatric parameters (i.e., type II error). We also need to emphasize that, given the exploratory nature of our study, the reported results are not corrected for multiple testing. In case of $p$-level adjustments, however, the observed associations would largely lose statistical significance. When controlling for factors that could additionally influence cognitive functioning (such as age, educational level, and sex), observed relationships likewise disappeared and sNfL did not predict any of the assessed cognitive and neuropsychiatric parameters, indicating that other parameters explain more variance of the outcome.

Taken together, we did not explore a clear link between sNfL and any cognitive test score, fatigue, depression, or anxiety levels. From a methodological perspective, these results can barely be attributed to an overly narrow selection of assessment scales and tools. We applied an extensive neuropsychological battery, not only covering various cognitive tests but also fatigue and affective self-report scales, assessing largely every neuropsychological domain NfL could potentially be associated with. Of interest, there are also other investigations that did not find CSF or sNfL to relate with cognitive performances $^{20,22}$ or with baseline fatigue. ${ }^{21}$ Of note, they all examined cohorts consisting of patients with CIS or patients with recently diagnosed RRMS suggestive of low disease activity, in contrast to the studies mentioned above showing positive results. In this context, it should be highlighted that $\mathrm{NfL}$ was seen as a measure of acute inflammation, given its transitory increase during relapses. ${ }^{37}$ Most of our patients though were currently treated with DMTs known to effectively reduce disease progression and blood NfL levels. ${ }^{35,38}$ We found cognitive performance (especially in the domains of attention and information processing, as well as verbal and visuospatial learning and memory) instead to be correlated with MRI variables, with much stronger effect sizes than relations between sNfL and cognition or between sNfL and MRI (table e-1, links. lww.com/NXI/A311). Measures such as lesion load and atrophy of brain structures reflect accumulated damage over time and therefore might constitute better predictors of functional outcomes, which are assessed in the absence of acute disease activity. A recent study further indicated that NfL concentrations derived from CSF better mirror MS-related neuronal damage and degeneration than sNfL measures. ${ }^{39}$ Of note, the authors investigated a cohort with a similar size as compared to our population. As Håkansson and colleagues state "... levels of brain-derived markers in the blood still constitute a proxy for the levels in [the] CSF where CNS pathology may be better represented, at least in smaller cohorts...."

Considering all discussed aspects together, our results suggest that for populations with rather modest clinical manifestations and no acute disease activity, NfL measured from serum does not seem to be a surrogate biomarker for cognitive performance and neuropsychiatric symptoms. With the perspective of being applied in clinical contexts, the sensitivity of sNfL as a single measure for such complex functional outcomes particularly within small samples outside of large scientific trials is questioned and needs to be further examined in future studies.

\section{Acknowledgment}

The authors thank all the patients for participating in this study and all colleagues from the Department of Neurology at the Heinrich Heine University, namely, Katharina Wagner-Berres and Melanie Kraft for blood draw, Annette $\mathrm{He} ß$ for handling the blood samples, Erika Raedisch and Anke Jelonek for their support in MRI data acquisition and processing, as well as Anja Felten, Dagmar Schulte, and all the physicians for taking care of the patients. They also thank Carolin Balloff (Heinrich Heine University, Düsseldorf) for her support in data collection.

\section{Study funding}

This research was financially supported in part by Teva.

\section{Disclosure}

O. Aktas received support from the German Ministry for Education and Research (BMBF) as part of the "German Competence Network Multiple Sclerosis” (KKNMS; FKZ 01GI1602B), as well as fees from Almirall, Bayer Healthcare, 
Biogen, Merck, Roche, Sanofi-Genzyme, and Teva for speaker services and advisory boards, and research grants from Biogen, Merck, and Sanofi-Genzyme. A. Renner, A. Huss, M. Filser, S. Baetge, N. Stute, M. Gasis, and K. Lepka report no disclosures relevant to the manuscript. N. Goebels has received honoraria for speaking at scientific meetings, serving at scientific advisory boards, travel, and/or research support from Biogen, BMBF, HHU-Forschungskommission, iBrain, International Progressive MS Alliance, Novartis, Roche, Sanofi-Genzyme, and Wellcome Trust. M. Senel has received consulting and speaker honoraria as well as travel reimbursements from Bayer, Biogen, Celgene, Roche, SanofiGenzyme, and Teva; she has received research funding from the Hertha-Nathorff-Program. J. Graf reports travel/meeting/ accommodation reimbursements from Biogen, Merck Serono, and Sanofi-Genzyme. C. Enzinger received funding for traveling and speaker honoraria from Biogen Idec, Bayer Schering Pharma, Merck Serono, Novartis, Genzyme, and Teva Pharmaceutical Industries Ltd./Sanofi-Aventis, Shire; received research support from Merck Serono, Biogen Idec, and Teva Pharmaceutical Industries Ltd./Sanofi-Aventis; and serves on scientific advisory boards for Bayer Schering Pharma, Biogen Idec, Merck Serono, Novartis, Genzyme, Roche, and Teva Pharmaceutical Industries Ltd./SanofiAventis. D. Pinter has received speaker honoraria and travel reimbursement from Biogen, Merck, and Sanofi-Genzyme. G. Antoch and B. Turowski report no disclosures relevant to the manuscript. H.-P. Hartung reports fees for consulting, speaking, and serving on steering committees from Bayer HealthCare, Biogen, GeNeuro, MedImmune, Merck, Novartis, Opexa, Receptos Celgene, Roche, Sanofi-Genzyme, CSL Behring, Octapharma, and Teva, with approval by the Rector of Heinrich Heine University. P. Albrecht has received compensation for serving on Scientific Advisory Boards for Ipsen, Novartis, and Biogen; he received speaker honoraria and travel support from Novartis, Teva, Biogen, Merz Pharmaceuticals, Ipsen, Allergan, Bayer HealthCare, Esai, UCB, and GlaxoSmithKline; he received research support from Allergan, Biogen, Ipsen, Novartis, Teva, Merz Pharmaceuticals, and Roche. M. Otto has received support from the German Ministry for Education and Research (BMBF) as part of the "German Competence Network Neurodegenerative dementias" (FTLDc), PreFrontALS, EU (Fairpark II); he gave scientific advice for Roche, Axon, Fujirebio, and Ionis. $\mathrm{H}$. Tumani reports funding for research projects, lectures and travel from Bayer, Biogen, Genzyme, Fresenius, Merck, Mylan, Novartis, Roche, Siemens Health Diagnostics, and Teva, and received research support from Hertie-Stiftung, DMSG, and BMBF. I.-K. Penner has received honoraria for speaking at scientific meetings, serving at scientific advisory boards and consulting activities from Adamas Pharma, Almirall, Bayer Pharma, Biogen, Celgene, Desitin, Genzyme, Janssen, Merck, Novartis, Roche, and Teva. She has received research support from the German MS Society, Celgene, Teva, and Novartis. All listed potential conflicts of interest are outside the context of this article's research, authorship and publication. Go to Neurology.org/NN for full disclosures.

\section{Publication history}

Received by Neurology: Neuroimmunology \& Neuroinflammation April 2, 2020. Accepted in final form August 10, 2020.

\begin{tabular}{lll} 
Appendix & Authors & \\
\hline Name & Location & Contribution \\
\hline $\begin{array}{l}\text { Orhan } \\
\text { Aktas, MD }\end{array}$ & $\begin{array}{l}\text { Department of Neurology, } \\
\text { Medical Faculty, University } \\
\text { Düsseldorf, Germany }\end{array}$ & $\begin{array}{l}\text { Study design and } \\
\text { conceptualization, } \\
\text { data acquisition and } \\
\text { analysis and interpretation, } \\
\text { literature research, } \\
\text { manuscript drafting, } \\
\text { and critical revision and } \\
\text { approval of the final } \\
\text { version of the manuscript }\end{array}$ \\
\hline $\begin{array}{l}\text { Alina } \\
\text { Renner, } \\
\text { MSc }\end{array}$ & $\begin{array}{l}\text { Cogito Center for Applied } \\
\text { Neurocognition and } \\
\text { Neuropsychological } \\
\text { Research, Düsseldorf, } \\
\text { Germany }\end{array}$ & $\begin{array}{l}\text { Data acquisition and } \\
\text { management, literature } \\
\text { research, statistical analysis } \\
\text { and interpretation, } \\
\text { manuscript drafting, and } \\
\text { critical revision and } \\
\text { approval of the final version } \\
\text { of the manuscript }\end{array}$ \\
\hline
\end{tabular}

\begin{tabular}{lll}
\hline André & Department of Neurology, \\
Huss, PhD & $\begin{array}{l}\text { University Hospital Ulm, } \\
\text { Germany }\end{array}$ & $\begin{array}{l}\text { sNftata analysis, and } \\
\text { critical revision and } \\
\text { approval of the final version } \\
\text { of the manuscript }\end{array}$ \\
\hline
\end{tabular}

\begin{tabular}{lll}
\hline Melanie & Cogito Center for Applied & Data acquisition and \\
Filser, MSc & Neurocognition and & management, statistical \\
& Neuropsychological & analysis and interpretation, \\
Research, Düsseldorf, & and critical revision and \\
Germany & approval of the final version \\
& of the manuscript
\end{tabular}

\begin{tabular}{lll}
\hline Sharon & Cogito Center for Applied & Data acquisition and \\
Baetge, & Neurocognition and & management, and critical \\
MSc & Neuropsychological & revision and approval of the \\
& Research, Düsseldorf, & $\begin{array}{l}\text { final version of the } \\
\text { manuscript }\end{array}$ \\
& Germany & .
\end{tabular}

\begin{tabular}{lll}
\hline Nathalie & Cogito Center for Applied & Data acquisition and \\
Stute, MSc & Neurocognition and & management, and critical \\
& Neuropsychological & revision and approval of the \\
& Research, Düsseldorf, & final version of the \\
& Germany & manuscript
\end{tabular}

\begin{tabular}{lll}
\hline Marcia & Department of Neurology, & Data acquisition and \\
Gasis, MSc & Medical Faculty, University \\
Düsseldorf, Germany & $\begin{array}{l}\text { management, and critical } \\
\text { revision and approval of the } \\
\text { final version of the } \\
\text { manuscript }\end{array}$ \\
\hline
\end{tabular}

Klaudia Department of Neurology, Data acquisition and

Lepka, Medical Faculty, University management, and critical

PhD Düsseldorf, Germany revision and approval of the final version of the manuscript

\begin{tabular}{lll}
\hline $\begin{array}{l}\text { Norbert } \\
\text { Goebels, } \\
\text { MD }\end{array}$ & $\begin{array}{l}\text { Department of Neurology, } \\
\text { Medical Faculty, University } \\
\text { Düsseldorf, Germany }\end{array}$ & $\begin{array}{l}\text { Data acquisition, and critical } \\
\text { revision and approval of the } \\
\text { final version of the } \\
\text { manuscript }\end{array}$ \\
\hline $\begin{array}{l}\text { Makbule } \\
\text { Senel, MD }\end{array}$ & $\begin{array}{l}\text { Department of Neurology, } \\
\text { University Hospital Ulm, } \\
\text { Germany }\end{array}$ & $\begin{array}{l}\text { sNfL data analysis, and } \\
\text { critical revision and } \\
\text { approval of the final version } \\
\text { of the manuscript }\end{array}$ \\
\hline $\begin{array}{l}\text { Jonas } \\
\text { Graf, MD }\end{array}$ & $\begin{array}{l}\text { Department of Neurology, } \\
\text { Medical Faculty, University } \\
\text { Düsseldorf, Germany }\end{array}$ & $\begin{array}{l}\text { Data acquisition, and critical } \\
\text { revision and approval of the } \\
\text { final version of the } \\
\text { manuscript }\end{array}$ \\
\hline
\end{tabular}


Appendix (continued)

\begin{tabular}{|c|c|c|}
\hline Name & Location & Contribution \\
\hline $\begin{array}{l}\text { Christian } \\
\text { Enzinger, } \\
\text { MD }\end{array}$ & $\begin{array}{l}\text { Department of Neurology, } \\
\text { Research Unit for Neuronal } \\
\text { Plasticity and Repair, } \\
\text { Medical University of Graz, } \\
\text { Graz, Austria; Division of } \\
\text { Neuroradiology, Vascular } \\
\text { and Interventional } \\
\text { Radiology, Department of } \\
\text { Radiology, Medical } \\
\text { University of Graz, Austria }\end{array}$ & $\begin{array}{l}\text { MRI data analysis, and } \\
\text { critical revision and } \\
\text { approval of the final version } \\
\text { of the manuscript }\end{array}$ \\
\hline $\begin{array}{l}\text { Daniela } \\
\text { Pinter, } \\
\text { PhD }\end{array}$ & $\begin{array}{l}\text { Department of Neurology, } \\
\text { Research Unit for Neuronal } \\
\text { Plasticity and Repair, } \\
\text { Medical University of Graz, } \\
\text { Austria }\end{array}$ & $\begin{array}{l}\text { MRI data analysis, and } \\
\text { critical revision and } \\
\text { approval of the final version } \\
\text { of the manuscript }\end{array}$ \\
\hline $\begin{array}{l}\text { Gerald } \\
\text { Antoch, } \\
\text { MD }\end{array}$ & $\begin{array}{l}\text { Department of Diagnostic } \\
\text { and Interventional } \\
\text { Radiology, Medical Faculty, } \\
\text { University Düsseldorf, } \\
\text { Germany }\end{array}$ & $\begin{array}{l}\text { MRI data acquisition and } \\
\text { analysis, and critical revision } \\
\text { and approval of the final } \\
\text { version of the manuscript }\end{array}$ \\
\hline $\begin{array}{l}\text { Bernd } \\
\text { Turowski, } \\
\text { MD }\end{array}$ & $\begin{array}{l}\text { Department of Diagnostic } \\
\text { and Interventional } \\
\text { Radiology, Medical Faculty, } \\
\text { University Düsseldorf, } \\
\text { Germany }\end{array}$ & $\begin{array}{l}\text { MRI data acquisition and } \\
\text { analysis, and critical revision } \\
\text { and approval of the final } \\
\text { version of the manuscript }\end{array}$ \\
\hline $\begin{array}{l}\text { Hans- } \\
\text { Peter } \\
\text { Hartung, } \\
\text { MD }\end{array}$ & $\begin{array}{l}\text { Department of Neurology, } \\
\text { Medical Faculty, University } \\
\text { Düsseldorf, Germany }\end{array}$ & $\begin{array}{l}\text { Study design and } \\
\text { conceptualization, } \\
\text { and critical revision and } \\
\text { approval of the final version } \\
\text { of the manuscript }\end{array}$ \\
\hline
\end{tabular}

\begin{tabular}{|c|c|c|}
\hline $\begin{array}{l}\text { Philipp } \\
\text { Albrecht, } \\
\text { MD }\end{array}$ & $\begin{array}{l}\text { Department of Neurology, } \\
\text { Medical Faculty, University } \\
\text { Düsseldorf, Germany }\end{array}$ & $\begin{array}{l}\text { Data acquisition, and critical } \\
\text { revision and approval of the } \\
\text { final version of the } \\
\text { manuscript }\end{array}$ \\
\hline $\begin{array}{l}\text { Markus } \\
\text { Otto, MD }\end{array}$ & $\begin{array}{l}\text { Department of Neurology, } \\
\text { University Hospital Ulm, } \\
\text { Germany }\end{array}$ & $\begin{array}{l}\text { sNfL data analysis, and } \\
\text { critical revision and } \\
\text { approval of the final version } \\
\text { of the manuscript }\end{array}$ \\
\hline $\begin{array}{l}\text { Hayrettin } \\
\text { Tumani, } \\
\text { MD }\end{array}$ & $\begin{array}{l}\text { Department of Neurology, } \\
\text { University Hospital Ulm, } \\
\text { Germany; Dietenbronn, } \\
\text { Ulm, Germany }\end{array}$ & $\begin{array}{l}\text { sNfL data analysis, and } \\
\text { critical revision and } \\
\text { approval of the final version } \\
\text { of the manuscript }\end{array}$ \\
\hline $\begin{array}{l}\text { Iris- } \\
\text { Katharina } \\
\text { Penner, } \\
\text { PhD }\end{array}$ & $\begin{array}{l}\text { Department of Neurology, } \\
\text { Medical Faculty, University } \\
\text { Düsseldorf; Cogito Center } \\
\text { for Applied Neurocognition } \\
\text { and Neuropsychological } \\
\text { Research, Düsseldorf, } \\
\text { Germany }\end{array}$ & $\begin{array}{l}\text { Literature research, study } \\
\text { design and } \\
\text { conceptualization, } \\
\text { acquisition of funding, data } \\
\text { analysis and interpretation, } \\
\text { manuscript drafting, and } \\
\text { critical revision and } \\
\text { approval of the final version } \\
\text { of the manuscript }\end{array}$ \\
\hline
\end{tabular}

\section{References}

1. Langdon DW. Cognition in multiple sclerosis. Curr Opin Neurol 2011;24:244-249.

2. Schulz D, Kopp B, Kunkel A, et al. Cognition in the early stage of multiple sclerosis. J Neurol 2006;253:1002-1010.

3. Dineen RA, Vilisaar J, Hlinka J, et al. Disconnection as a mechanism for cognitive dysfunction in multiple sclerosis. Brain 2009;132:239-249.

4. Schoonheim MM, Meijer KA, Geurts JJG. Network collapse and cognitive impairment in multiple sclerosis. Front Neurol 2015;6:82.

5. Tartaglia MC, Narayanan S, Francis SJ, et al. The relationship between diffuse axonal damage and fatigue in multiple sclerosis. Arch Neurol 2004;61:201-207.

6. Corallo F, Lo Buono V, Genovese R, et al. A complex relation between depression and multiple sclerosis: a descriptive review. Neurol Sci 2019;40:1551-1558.

7. Romero K, Shammi P, Feinstein A. Neurologists' accuracy in predicting cognitive impairment in multiple sclerosis. Mult Scler Relat Disord 2015;4:291-295.
8. Petzold A. Neurofilament phosphoforms: surrogate markers for axonal injury, degeneration and loss. J Neurol Sci 2005;233:183-198.

9. Bridel C, van Wieringen WN, Zetterberg $\mathrm{H}$, et al. Diagnostic value of cerebrospinal fluid neurofilament light protein in Neurology. JAMA Neurol 2019;76:1035-1048.

10. Lycke JN, Karlsson JE, Andersen O, et al. Neurofilament protein in cerebrospinal fluid: a potential marker of activity in multiple sclerosis. J Neurol Neurosurg Psychiatry 1998;64:402-404.

11. Gunnarsson M, Malmeström C, Axelsson M, et al. Axonal damage in relapsing multiple sclerosis is markedly reduced by natalizumab. Ann Neurol 2011;69:83-89.

12. Kuhle J, Malmeström C, Axelsson M, et al. Neurofilament light and heavy subunits compared as therapeutic biomarkers in multiple sclerosis. Acta Neurol Scand 2013; 128:33-36.

13. Rissin DM, Kan CW, Campbell TG, et al. Single-molecule enzyme-linked immunosorbent assay detects serum proteins at subfemtomolar concentrations. Nat Biotechnol 2010;28:595-599.

14. Khalil M, Teunissen CE, Otto M, et al. Neurofilaments as biomarkers in neurological disorders. Nat Rev Neurol 2018;14:577-589.

15. Disanto G, Barro C, Benkert P, et al. Serum Neurofilament light: a biomarker of neuronal damage in multiple sclerosis. Ann Neurol 2017;81:857-870.

16. Thebault $\mathrm{S}$, Tessier DR, Lee $\mathrm{H}$, et al. High serum neurofilament light chain normalizes after hematopoietic stem cell transplantation for MS. Neurol Neuroimmunol Neuroinflamm 2019;6:e598.

17. Gaetani L, Salvadori N, Lisetti V, et al. Cerebrospinal fluid neurofilament light chain tracks cognitive impairment in multiple sclerosis. J Neurol 2019;266:2157-2163.

18. Quintana E, Coll C, Salavedra-Pont J, et al. Cognitive impairment in early stages of multiple sclerosis is associated with high cerebrospinal fluid levels of chitinase 3-like 1 and neurofilament light chain. Eur J Neurol 2018;25:1189-1191.

19. Kalatha T, Arnaoutoglou M, Koukoulidis T, et al. Does cognitive dysfunction correlate with neurofilament light polypeptide levels in the CSF of patients with multiple sclerosis? J Int Med Res 2019;47:2187-2198.

20. Chitnis T, Gonzalez C, Healy BC, et al. Neurofilament light chain serum levels correlate with 10-year MRI outcomes in multiple sclerosis. Ann Clin Transl Neurol 2018;5:1478-1491.

21. Hakansson I, Johansson L, Dahle C, et al. Fatigue scores correlate with other selfassessment data, but not with clinical and biomarker parameters, in CIS and RRMS Mult Scler Relat Disord 2019;36:101424.

22. Tortorella C, Direnzo V, Taurisano P, et al. Cerebrospinal fluid neurofilament tracks fMRI correlates of attention at the first attack of multiple sclerosis. Mult Scler 2015; 21:396-401.

23. Kurtzke JF. Rating neurologic impairment in multiple sclerosis: an expanded disability status scale (EDSS). Neurology 1983;33:1444-1452.

24. Schmidt P, Gaser C, Arsic M, et al. An automated tool for detection of FLAIRhyperintense white-matter lesions in multiple sclerosis. Neuroimage 2012;59: 3774-3783.

25. Jenkinson M, Beckmann CF, Behrens TEJ, et al. Review FSL. Neuroimage 2012;62: 782-790.

26. Abdelhak A, Huss A, Kassubek J, et al. Serum GFAP as a biomarker for disease severity in multiple sclerosis. Sci Rep 2018;8:14798.

27. Dusankova JB, Kalincik T, Havrdova E, et al. Cross cultural validation of the Minimal Assessment of Cognitive Function in Multiple Sclerosis (MACFIMS) and the Brief International Cognitive Assessment for Multiple Sclerosis (BICAMS). Clin Neuropsychol 2012;26:1186-1200.

28. Hyun JW, Kim Y, Kim G, et al. Longitudinal analysis of serum neurofilament light chain: a potential therapeutic monitoring biomarker for multiple sclerosis. Mult Scler J 2020;26:659-667.

29. Matias-Guiu JA, Cortés-Martínez A, Valles-Salgado M, et al. Functional components of cognitive impairment in multiple sclerosis: a cross-sectional investigation. Front Neurol 2017;8:643.

30. Ruano L, Portaccio E, Goretti B, et al. Age and disability drive cognitive impairment in multiple sclerosis across disease subtypes. Mult Scler J 2017;23:1258-1267.

31. Popescu V, Agosta F, Hulst HE, et al. Brain atrophy and lesion load predict long term disability in multiple sclerosis. J Neurol Neurosurg Psychiatry 2013;84:1082-1091.

32. Hulst HE, Steenwijk MD, Versteeg A, et al. Cognitive impairment in MS: impact of white matter integrity, gray matter volume, and lesions. Neurology 2013;80:1025-1032.

33. Migliore S, Ghazaryan A, Simonelli I, et al. Validity of the minimal assessment of cognitive function in multiple sclerosis (MACFIMS) in the Italian population. Neurol Sci 2016;37:1261-1270.

34. Planche V, Gibelin M, Cregut D, et al. Cognitive impairment in a population-based study of patients with multiple sclerosis: differences between late relapsing-remitting, secondary progressive and primary progressive multiple sclerosis. Eur J Neurol 2016; 23:282-289.

35. Delcoigne B, Manouchehrinia A, Barro C, et al. Blood neurofilament light levels segregate treatment effects in multiple sclerosis. Neurology 2020;94:e1201-e1212.

36. Jakimovski D, Zivadinov R, Ramanathan $M$, et al. Serum neurofilament light chain levels and cognitive performance in multiple sclerosis: a longitudinal retrospective 5year study. Mult Scler J Epub 2019 Oct 15.

37. Domingues RB, Bruniera G, Fernandes P, et al. Neurofilament light chain in the assessment of patients with multiple sclerosis. Arq Neuropsiquiatr 2019;77:436-441.

38. Torkildsen $\mathrm{O}, \mathrm{Myhr} \mathrm{KM}, \mathrm{B} ø \mathrm{~L}$. Disease-modifying treatments for multiple sclerosis: a review of approved medications. Eur J Neurol 2016;23:18-27.

39. Håkansson I, Tisell A, Cassel P, et al. Neurofilament levels, disease activity and brain volume during follow-up in multiple sclerosis. J Neuroinflammation 2018;15:209. 


\title{
Neurology \\ Neuroimmunology \& Neuroinflammation
}

\author{
Serum neurofilament light chain: No clear relation to cognition and neuropsychiatric \\ symptoms in stable MS \\ Orhan Aktas, Alina Renner, André Huss, et al. \\ Neurol Neuroimmunol Neuroinflamm 2020;7; \\ DOI 10.1212/NXI.0000000000000885
}

This information is current as of September 24, 2020

Updated Information \&

Services

References

Subspecialty Collections

Permissions \& Licensing

Reprints including high resolution figures, can be found at:

http://nn.neurology.org/content/7/6/e885.full.html

This article cites 38 articles, 3 of which you can access for free at: http://nn.neurology.org/content/7/6/e885.full.html\#\#ref-list-1

This article, along with others on similar topics, appears in the following collection(s):

Multiple sclerosis

http://nn.neurology.org//cgi/collection/multiple_sclerosis

Neuropsychological assessment

http://nn.neurology.org//cgi/collection/neuropsychological_assessment

Information about reproducing this article in parts (figures,tables) or in its entirety can be found online at:

http://nn.neurology.org/misc/about.xhtml\#permissions

Information about ordering reprints can be found online:

http://nn.neurology.org/misc/addir.xhtml\#reprintsus

Neurol Neuroimmunol Neuroinflamm is an official journal of the American Academy of Neurology.

Published since April 2014, it is an open-access, online-only, continuous publication journal. Copyright

Copyright (C) 2020 The Author(s). Published by Wolters Kluwer Health, Inc. on behalf of the American

Academy of Neurology.. All rights reserved. Online ISSN: 2332-7812.

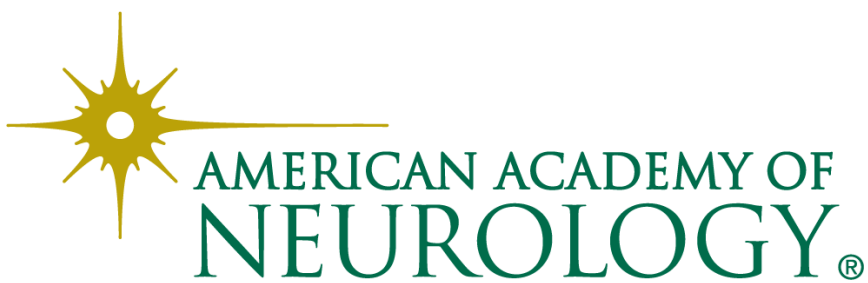

